\title{
Genetic Structure of Atmospheric Populations of Gibberella zeae
}

\author{
David G. Schmale III, John F. Leslie, Kurt A. Zeller, Amgad A. Saleh, Elson J. Shields, and Gary C. Bergstrom
}

First and sixth authors: Department of Plant Pathology, Cornell University, Ithaca, NY 14853; second and fourth authors: Department of Plant Pathology, Kansas State University, Manhattan 66506; third author: U.S. Department of Agriculture-APHIS-PPQ-CPHST, Plant Germplasm Quarantine and Biotechnology Laboratory, Beltsville, MD 20705; and fifth author: Department of Entomology, Cornell University, Ithaca, NY 14853.

Current address of D. G. Schmale III: Department of Plant Pathology, Physiology, and Weed Science, Virginia Polytechnic Institute and

State University, Blacksburg, VA 24061.

Accepted for publication 17 April 2006.

\begin{abstract}
Schmale, D. G., III, Leslie, J. F., Zeller, K. A., Saleh, A. A., Shields, E. J., and Bergstrom, G. C. 2006. Genetic structure of atmospheric populations of Gibberella zeae. Phytopathology 96:1021-1026.

Gibberella zeae, causal agent of Fusarium head blight (FHB) of wheat and barley and Gibberella ear rot (GER) of corn, may be transported over long distances in the atmosphere. Epidemics of FHB and GER may be initiated by regional atmospheric sources of inoculum of G. zeae; however, little is known about the origin of inoculum for these epidemics. We tested the hypothesis that atmospheric populations of G. zeae are genetically diverse by determining the genetic structure of New York atmospheric populations (NYAPs) of G. zeae, and comparing them with populations of $G$. zeae collected from seven different states in the northern United States. Viable, airborne spores of G. zeae were collected in rotational (lacking any apparent within-field inoculum sources of G. zeae) wheat and corn fields in Aurora, NY in May through August over 3 years (2002 to 2004). We evaluated 23 amplified fragment length polymorphism (AFLP) loci in 780 isolates of G. zeae. Normalized genotypic diversity was high (ranging from 0.91 to 1.0 ) in NYAPs of G. zeae, and

Although the NYAPs were genotypically diverse, they were genetically similar and potentially part of a large, interbreeding population of G. zeae in North America. Estimates of the fixation index $\left(G_{\mathrm{ST}}\right)$ and the effective migration rate $(\mathrm{Nm})$ for the NYAPs indicated significant genetic exchange among populations. Relatively low levels of linkage disequilibrium in the NYAPs suggest that outcrossing is common and that the populations are not a result of a recent bottleneck or invasion. When NYAPs were compared with those collected across the United States, the observed genetic identities between the populations ranged from 0.92 to 0.99 . However, there was a significant negative correlation $(R=-0.59, P<0.001)$ between genetic identity and geographic distance, suggesting that some genetic isolation may occur on a continental scale. The contribution of long-distance transport of G. zeae to regional epidemics of FHB and GER remains unclear, but the diverse atmospheric populations of $G$. zeae suggest that inoculum may originate from multiple locations over large geographic distances. Practically, the long-distance transport of G. zeae suggests that management of inoculum sources on a local scale, unless performed over extensive production areas, will not be completely effective for the management of FHB and GER.
\end{abstract} nearly all of the isolates in each of the populations represented unique AFLP haplotypes. Pairwise calculations of Nei's unbiased genetic identity were uniformly high ( $>0.99$ ) for all of the possible NYAP comparisons.
Additional keywords: aerobiology, Fusarium graminearum, gene flow maize, random mating, scab.
Population genetic analyses have been used to test hypotheses concerning the origin (16) and distribution (23) of plant pathogen populations. Population genetic structure may be used to infer sources of inoculum for local epidemics (2), and may aid in the development of strategies for disease management (3). An increased understanding of the genetic structure of plant pathogen populations is a prerequisite to developing innovative, rational, and informed approaches to managing plant diseases (29).

Gibberella zeae (Schwein.) Petch (anamorph Fusarium graminearum Schwabe) is the primary causal agent of Fusarium head blight (FHB) of wheat and barley (1) and Gibberella ear rot (GER) of corn (48) in North America. FHB and GER are particularly important because grain infested with $G$. zeae often is contaminated with trichothecene mycotoxins that threaten the health of both humans and domesticated animals $(27,36)$.

Corresponding author: G. C. Bergstrom; E-mail address: gcb3@ cornell.edu

* The $\boldsymbol{e}$-Xtra logo stands for "electronic extra" and indicates that the online version contains supplemental material not included in the print edition. The online version contains a table in which two-locus linkage disequalibrium is calculated for atmospheric populations of $G$. zeae using 72 paired loci.

\section{DOI: 10.1094/PHYTO-96-1021}

This article is in the public domain and not copyrightable. It may be freely reprinted with customary crediting of the source. The American Phytopathological Society, 2006
Ascospores of G. zeae are transported through the atmosphere to susceptible host plants $(1,38,39,46)$. Epidemics of FHB and GER may be initiated by regional atmospheric sources of inoculum of $G$. zeae $(8,42,43,45)$; however, little is known about the origin of inoculum for FHB and GER and how far the inoculum may travel from its source. Recent evidence suggests that G. zeae may be transported through the atmosphere over long distances $(15,24)$.

Decreases in tillage may have contributed to recent epidemics of FHB (27) and GER (14) by increasing the amount of regional atmospheric inoculum available for infection. Where a large, regional source of atmospheric inoculum exists, crop rotation or tillage practices may not effectively reduce the risk of FHB or GER in individual fields. An increased understanding of the genetic structure of regional atmospheric populations of $G$. zeae may aid in developing or excluding strategies for managing FHB and GER.

Studies of the genetic structure of populations of G. zeae collected from infected cereals in the United States have demonstrated that these populations are genetically diverse (50,52,53). A study by Zeller et al. (53) examined the population genetic structure of eight populations (523 isolates) of G. zeae isolated from infected cereals across the United States. All of the populations were genotypically diverse, and extensive interpopulation genetic exchange appeared to have occurred across large geographic 
distances (53). Epidemic populations of G. zeae in the United States may be part of a large, interbreeding population of the pathogen in North America $(52,53)$.

Based on data from Walker et al. (50) and Zeller et al. (52,53), we hypothesized that atmospheric populations of $G$. zeae are genetically diverse (i.e., that inoculum for regional epidemics of FHB and GER comes from a well-mixed atmospheric population of $G$. zeae, potentially originating from multiple locations and mixed over large geographic distances). We tested this hypothesis by examining the genetic structure of New York atmospheric populations (NYAPs) of G. zeae, and comparing the structure of the NYAPs with the populations of $G$. zeae collected from infected cereals by Zeller et al. (53) from seven different states across the continental United States.

The specific objectives of this study were to (i) assess the genetic diversity in NYAPs of G. zeae; (ii) determine whether the NYAPs were part of a large, interbreeding population of $G$. zeae in North America; (iii) observe potential population differentiation between the NYAPs of $G$. zeae and populations collected by Zeller et al. (53) across the continental United States; and (iv) examine the potential contribution of long-distance transport to NYAPs of G. zeae. This study provides the first detailed description of the genetic structure of atmospheric populations of G. zeae.

\section{MATERIALS AND METHODS}

Isolate collection and identification. Viable, airborne spores of $G$. zeae were collected (Table 1) on petri plates containing a Fusarium-selective medium (FSM) placed in rotational (lacking any apparent within-field inoculum sources of G. zeae) wheat and corn fields at the Robert B. Musgrave Research Farm in Aurora, NY $(40,42,43,45)$. FSM was the Nash-Snyder medium described by Burgess et al. (7), but with neomycin sulfate increased to $0.175 \mathrm{~g} /$ liter. Petri plates were exposed continuously from sunrise to sunset (approximately 6:00 a.m. to 8:00 p.m.), and from sunset to sunrise (approximately 8:00 p.m. to 6:00 a.m.). Following exposure in the field, the petri plates were collected, covered, and returned to the laboratory where they were incubated for 5 to 7 days at room temperature $\left(22^{\circ} \mathrm{C}\right)$ under ambient light conditions. Salmon colored colonies typical of $F$. graminearum were subcultured onto fresh plates of FSM, transferred to carnation leaf agar (13), and single-spored onto potato dextrose agar (PDA) (Difco Laboratories, Detroit). Single-spored cultures were transferred to sterile filter paper on PDA, dried in a laminar flow hood for 3 days, and placed in sterile envelopes at $4^{\circ} \mathrm{C}$ until analyzed. An arbitrary sample of 150 single-spored isolates tentatively identified as $F$. graminearum were transferred to carrot agar $(5,19)$ to confirm that they produce the homothallic perfect stage of $G$. zeae. Cultures on carrot agar were incubated at room temperature for 4 days. Plates were flooded with $1 \mathrm{ml}$ of $2.5 \%$ Tween 60 and flattened with a bent glass rod (5). Cultures were evaluated 12 days later for the formation of perithecia.

DNA extraction. Isolates of $G$. zeae were grown in potato dextrose broth (6 $\mathrm{g}$ of Difco potato dextrose broth per liter of distilled water) for 4 days on a shaker at $150 \mathrm{rpm}$. The resulting mycelium was filtered through four layers of sterile cheesecloth and transferred to sterile 25-ml plastic centrifuge tubes. Mycelial samples were lyophilized for $24 \mathrm{~h}$ and stored at $-5^{\circ} \mathrm{C}$. DNA was extracted from the lyophilized mycelial samples with Qiagen's DNeasy Plant Mini-kit (Qiagen, Chatsworth, CA) according to the manufacturer's protocol.

Amplified fragment length polymorphisms. Amplified fragment length polymorphisms (AFLPs) were generated following standard protocols $(49,52,54)$. Three primer-pair combinations with two selective nucleotides on each primer were used: $\mathrm{Eco}+\mathrm{AA} / \mathrm{Mse}+\mathrm{AT}, \quad \mathrm{Eco}+\mathrm{CC} / \mathrm{Mse}+\mathrm{CG}$, and Eco+TG/Mse+TT (52,53). The labeling of EcoRI primers, separation of DNA fragments, and generation of autoradiographs were performed as previously described $(52,54)$.

Polymorphic AFLP bands ranging from 100 to 800 bp in length were scored manually. Each band was treated as a distinct locus, with two alleles. Because G. zeae is haploid, AFLP markers can be scored unambiguously as dominant (band present) or recessive (band absent) alleles. Bands of the same size from different isolates were assumed to be homologous and represent the same allele. AFLP data were recorded in a binary format (allele present $=1$ or absent $=0$ ). We included AFLPs from G. zeae lineages 1 to 7 (33) as standards on the gels.

Analysis of the genetic structure of the NYAPs. PAUP 4.10 beta (Sinauer Associates, Sunderland, MA) was used to identify distinct and clonal AFLP haplotypes within each NYAP. Allelic binary data were analyzed with unweighted pair grouping by mathematical averaging (UPGMA).

Genotypic diversity $(\hat{G})$ was calculated for each NYAP as previously described (28). Normalized genotypic diversity was calculated by dividing ( $\hat{G}$ ) by the number of unique AFLP haplotypes observed within each population.

Popgene version 1.32 was used to calculate unbiased measures of genetic identity and genetic distance (31), allele frequencies, Nei's gene diversity $(h)(30)$, fixation index $\left(G_{\mathrm{ST}}\right)(26)$, effective migration rate $(\mathrm{Nm})$ (32), two-locus linkage disequilibrium (51), and multilocus linkage disequilibrium (47). All AFLP data were analyzed as dominant markers occurring in haploid strains.

We performed $\chi^{2}$ tests to identify differences in allele frequencies at individual AFLP loci among all of the NYAPs of G. zeae. The null hypothesis of no difference in allele frequencies at each individual locus was rejected in favor of the alternative hypothesis (significant difference in allele frequencies) if $P<0.01$.

We assessed two-locus linkage disequilibrium at all 23 AFLP loci in each of the NYAPs (22). The null hypothesis of linkage equilibrium was rejected in favor of the alternative hypothesis (linkage disequilibrium) at $P<0.01$ or $P<0.05$ for our $\chi^{2}$ tests.

A multivariate correlation analysis was used to test for multilocus linkage disequilibrium across all 23 AFLP loci in each of the NYAPs (47). The null hypothesis of multilocus linkage equilibrium across all loci was rejected in favor of the alternative hypothesis (multilocus linkage disequilibrium across all loci) at $P<0.05$ for our $\chi^{2}$ tests.

Methods for comparing genetic structure among U.S. populations of $G$. zeae. Popgene was used to calculate pairwise comparisons of unbiased genetic identity and genetic distance

TABLE 1. Calculations of genotypic diversity $(\ddot{G})$ in four New York atmospheric populations of Gibberella zeae

\begin{tabular}{lccccc}
\hline Population $^{\mathrm{a}}$ & Dates collected & Isolates & Number of haplotypes & $\hat{G}^{\mathrm{b}}$ & $\hat{G}^{\mathrm{c}} / n^{\mathrm{c}}$ \\
\hline Wheat-2004 & 3-8 June & 81 & 80 & 79 & 0.988 \\
Corn-2004 & 5-11 August & 55 & 55 & 55 & 1.000 \\
Corn-2003 & 29 July-4 August & 59 & 59 & 59 & 1.000 \\
Wheat-2002 & 27 May-15 June & 62 & 58 & 53 & 0.914 \\
\hline
\end{tabular}

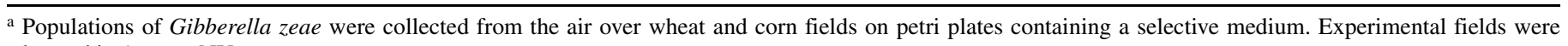
located in Aurora, NY.

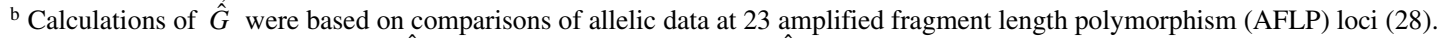

c Normalized genotypic diversity $(\hat{G} / \mathrm{n})$ was calculated by dividing $\hat{G}$ by the number $(n)$ of AFLP haplotypes in each population. 
(31) among 12 populations of G. zeae (four New York atmospheric populations, and eight populations from Zeller et al. [53]) across the United States. Calculations were based on allelic data from 23 AFLP loci. A correlation analysis was used to test the relatedness of genetic identity to geographical distance for each pairwise comparison between populations. The correlation analysis $(P<0.05)$ was performed using PROC CORR in SAS system for Windows (release 8.02; SAS Intitute, Cary, NC).

\section{RESULTS}

We analyzed AFLPs from 257 isolates of G. zeae collected from four NYAPs (Wheat-2004, Corn-2004, Corn-2003, and Wheat-2002) (Table 1). Individual population sizes ranged from 55 (Corn-2004) to 81 isolates (Wheat-2004). All 257 isolates had AFLP profiles typical of G. zeae lineage 7 (33).

We scored the presence or absence of alleles at 157 polymorphic AFLP loci generated from three different primer-pair combinations, but used data for only 23 loci in the population genetic analysis. These 23 loci have been localized on a published genetic map of G. zeae $(20,52,53)$, and both alleles at all of these loci were present at $>5 \%$ frequency in all of the populations. Zeller et al. (53) used the same set of 23 AFLP loci, which enables direct comparison of the two sets of results.

TABLE 2. Pairwise calculations of Nei's unbiased genetic identity (above diagonal) and genetic distance (below diagonal) (31) based on 23 amplified fragment length polymorphism loci for four New York atmospheric populations of Gibberella zeae ${ }^{\mathrm{a}}$

\begin{tabular}{lcccc}
\hline & Wheat-2004 & Corn-2004 & Corn-2003 & Wheat-2002 \\
\hline Wheat-2004 & $\ldots$ & 0.993 & 0.996 & 0.990 \\
Corn-2004 & 0.007 & $\ldots$ & 0.993 & 0.997 \\
Corn-2003 & 0.004 & 0.007 & $\ldots$ & 0.997 \\
Wheat-2002 & 0.010 & 0.003 & 0.004 & $\ldots$ \\
\hline
\end{tabular}

${ }^{\text {a }}$ Populations of G. zeae were collected from the air over wheat and corn fields in Aurora, NY.
Genetic structure of NYAPs. Nearly all (249/257) of the isolates in each of the NYAPs had a unique AFLP haplotype, and no haplotype was found in more than one NYAP. In Wheat-2004, a single haplotype was collected twice during the same sample period from different collection sites. In Wheat-2002, three haplotypes were each collected twice in different locations on different days. No haplotype was collected more than once in the NYAPs Corn-2003 and Corn-2004.

The normalized genotypic diversity for each of the NYAPs ranged from 0.914 to 1 (Table 1 ). The highest genotypic diversity occurred in the Corn-2004 and Corn-2003 populations, in which every isolate had a unique AFLP haplotype (Table 1). Pairwise comparisons of genetic identity and genetic distance between NYAPs were uniformly high (ranging from 0.990 to 0.997 ) and uniformly low (0.003 to 0.010$)$, respectively (Table 2$)$. The allele frequencies in the four NYAPs differed significantly from one another $(P<0.01)$ at only 1 of the 23 loci scored (EAAMAT0263K) (Table 3). Nei's gene diversity $(h)(30)$ ranged from 0.124 to 0.499 (Table 3), with an overall mean $h$ of 0.337 . The fixation index $\left(G_{\mathrm{ST}}\right)(26)$ ranged from 0.001 to 0.053 (Table 3 ), with an overall mean $G_{\mathrm{ST}}$ of 0.014 . The effective migration rate per generation $(\mathrm{Nm})$ (32) ranged from 9 to 411 (Table 3), with an overall mean of 35 .

Linkage disequilibrium in the NYAPs. For calculations of two-locus linkage disequilibrium in NYAPs (51), there were 253 possible pairwise comparisons for 23 AFLP loci. We rejected the null hypothesis of two-locus linkage equilibrium $(P<0.01)$ in favor of the alternative hypothesis of two-locus linkage disequilibrium for 10 pairs of loci (4\%) for the Wheat-2004 population, 8 pairs of loci (3\%) for the Corn-2004 population, 3 pairs of loci $(1 \%)$ for the Corn-2003 population, and 7 pairs of loci (3\%) for the Wheat-2002 population. We rejected the null hypothesis of two-locus linkage equilibrium $(P<0.05)$ in favor of the alternative hypothesis of two-locus linkage disequilibrium for 26 pairs of loci $(10 \%)$ for the Wheat-2004 population, 23 pairs of loci (9\%) for the Corn-2004 population, 16 pairs of loci $(6 \%)$ for the Corn-2003 population, and 26 pairs of loci (10\%) for the

TABLE 3. Population genetic structure and genetic differentiation among four New York atmospheric populations of Gibberella zea $e^{\text {a }}$

\begin{tabular}{|c|c|c|c|c|c|}
\hline Locus & Linkage group ${ }^{b}$ & Chromosome & Gene diversity ${ }^{\mathrm{c}}$ & Fixation index ${ }^{d}$ & Effective migration rate \\
\hline ECCMCG0652K & 2 & 3 & 0.327 & 0.005 & 105 \\
\hline ECCMCG0627K & 3 & 4 & 0.137 & 0.003 & 158 \\
\hline ECCMCG0210K & $?$ & $?$ & 0.263 & 0.007 & 70 \\
\hline ECCMCG0114K & 2 & 3 & 0.429 & 0.008 & 60 \\
\hline ECCMCG0109K & 4 & 1 & 0.252 & 0.009 & 50 \\
\hline EAAMAT0765K & 1 & 2 & 0.445 & 0.006 & 89 \\
\hline EАAМАТ0687K & 2 & 3 & 0.482 & 0.033 & 15 \\
\hline EAAMAT0513K & 2 & 3 & 0.455 & 0.003 & 182 \\
\hline ЕААМАТ0393K & 3 & 4 & 0.423 & 0.011 & 43 \\
\hline EAAMAT0376K & 3 & 4 & 0.268 & 0.009 & 54 \\
\hline EAAMAT0270K & 3 & 4 & 0.498 & 0.005 & 103 \\
\hline EAAMAT0263K & 1 & 2 & 0.468 & 0.053 & 9 \\
\hline ЕАAMAT0220K & $?$ & $?$ & 0.200 & 0.034 & 14 \\
\hline ЕАAМАТО199K & 3 & 4 & 0.460 & 0.003 & 169 \\
\hline ЕАAМАТО199K & 3 & 4 & 0.429 & 0.024 & 20 \\
\hline ЕААМАТ0188J & 3 & 4 & 0.374 & 0.040 & 12 \\
\hline ETGMTT0399K & 9 & 2 & 0.499 & 0.012 & 43 \\
\hline ETGMTT0395K & 2 & 3 & 0.130 & 0.009 & 58 \\
\hline ETGMTT0253K & 9 & 2 & 0.309 & 0.004 & 121 \\
\hline ETGMTT0249J & 7 & 2 & 0.130 & 0.001 & 411 \\
\hline ETGMTT0240K & 3 & 4 & 0.494 & 0.007 & 75 \\
\hline ETGMTT0171K & 6 & 1 & 0.124 & 0.005 & 100 \\
\hline ETGMTT0112J & 9 & 2 & 0.163 & 0.007 & 69 \\
\hline
\end{tabular}

${ }^{a}$ Calculations were based on allelic data from 23 amplified fragment length polymorphism loci.

b As determined by Jurgenson et al. (20).

c Calculated as Nei (30).

d Calculated as McDermott and McDonald (26).

e Calculated as Nei (32).

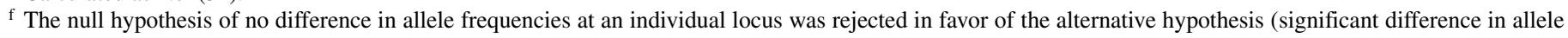
frequencies) if $P<0.01$. 
Wheat-2002 population. No pairs of loci demonstrated linkage disequilibrium across all four NYAPs. Four pairs of loci (pairs 13, 12, 42, and 56) demonstrated linkage disequilibrium across three NYAPs.

Average correlations between AFLP loci (as a measure for multilocus linkage disequilibrium) in each of the NYAPs are presented in Table 4. We rejected the null hypothesis of multilocus linkage equilibrium $(P<0.05)$ in favor of the alternative hypothesis of multilocus linkage disequilibrium for the populations Wheat-2004, Corn-2004, and Wheat-2002 (Table 4). We failed to reject the null hypothesis of multilocus linkage equilibrium for the Corn-2003 population $(P=0.069)$.

Genetic identity and geographic distance among U.S. populations. Pairwise calculations of Nei's unbiased genetic identity (31) for 12 populations of G. zeae (4 NYAPs and 8 populations from Zeller et al. [53]) across the United States were uniformly high (ranging from 0.925 to 0.997$)$ (Table 5). There was a significant negative correlation $(R=-0.59, P<0.001)$ between genetic identity and geographic distance among these U.S. populations (Fig. 1). Genetic identity was smaller (0.95 to 0.96$)$ in the comparisons between the four NYAPs and the NY populations from Zeller et al. (53) than in the comparisons between the four NYAPs (ranging from 0.99 to 1.00 ) (Table 5; Fig. 1).

\section{DISCUSSION}

Epidemics of FHB and GER may be initiated by regional atmospheric sources of inoculum of $G$. zeae $(8,42,43,45)$. Little is known about the origin of inoculum for regional epidemics of FHB and GER (whether from local or distant sources), or how far the inoculum travels. We used AFLPs to test the hypothesis that atmospheric populations of $G$. zeae are genetically diversepotentially originating from multiple locations and mixed over large geographic distances. Our observation of high genotypic diversity in atmospheric populations of G. zeae is consistent with

TABLE 4. Multivariate correlation analysis as a measure of multilocus linkage disequilibrium (47) across 23 amplified fragment length polymorphism (AFLP) loci in four New York atmospheric populations of Gibberella zeae

\begin{tabular}{lccccc}
\hline Population & Isolates & $\begin{array}{c}\text { Average } \\
\text { correlation }\end{array}$ & df & $\chi^{2}$ & Probability $^{\mathrm{a}}$ \\
\hline Wheat-2004 & 81 & 0.199 & 253 & 339 & $<0.001$ \\
Corn-2004 & 55 & 0.204 & 253 & 315 & 0.005 \\
Corn-2003 & 59 & 0.202 & 253 & 287 & 0.069 \\
Wheat-2002 & 62 & 0.204 & 253 & 378 & $<0.001$ \\
\hline
\end{tabular}

a The null hypothesis of multilocus linkage equilibrium across 23 AFLP loci was rejected in favor of the alternative hypothesis (multilocus linkage disequilibrium across 23 AFLP loci) if $P<0.01$. reports of high genotypic diversity in populations of G. zeae collected from infected cereals $(4,11,37,50,52,53)$. Our results are consistent with the hypothesis that genetic diversity in atmospheric populations is the same as that found in field populations of $G$. zeae.

G. zeae has been postulated to include at least nine phylogenetic lineages with various continental origins $(33,34)$. In the United States, populations of the pathogen are representative of G. zeae phylogenetic lineage $7(52,53)$ and appear to be composed of a single biological species (6). Populations of G. zeae collected from infected cereals in China appear to be a part of a large, interbreeding population representative of G. zeae phylogenetic lineage 6 (17). Zeller et al. (53) used AFLPs of 523 isolates of $G$. zeae, representing eight populations of the fungus collected from infected cereals across the United States. All of the analyzed isolates in this study and in Zeller et al. (53) had AFLP profiles representative of $G$. zeae phylogenetic lineage 7 . Calculations of genetic identity between NYAPs were uniformly high, and allele frequencies differed significantly among the NYAPs at only one locus. These results are consistent with the genetic similarity observed among populations of $G$. zeae collected from infected cereals over large geographic distances (up to approxi-

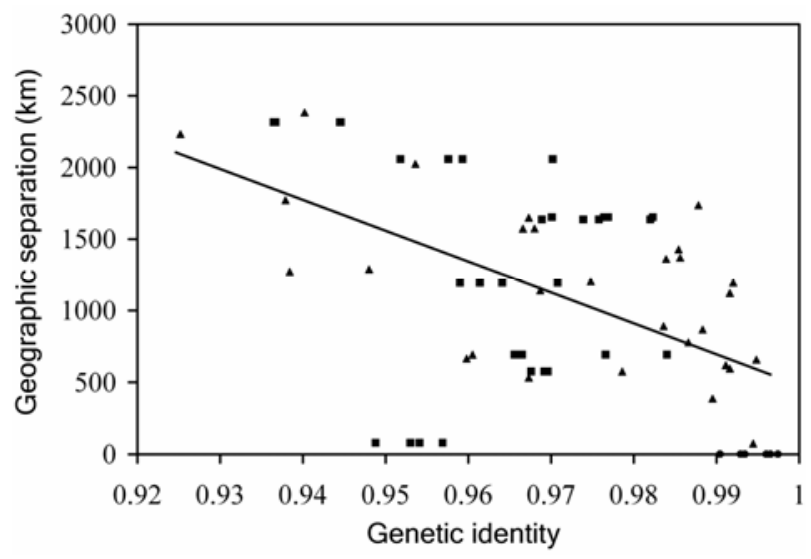

Fig. 1. Scatter plot of genetic identity and geographic separation $(\mathrm{km})$ for 12 populations of Gibberella zeae (4 New York atmospheric populations [NYAPs] and 8 populations from Zeller et al. [54]) across the United States. Pairwise comparisons were based on data from 23 amplified fragment length polymorphism loci and are represented in the figure as the following: between the four NYAPs (circles), between the four NYAPs and the eight populations from Zeller et al. (54) (squares), and between the eight populations from Zeller et al. (54) (triangles). There was a significant negative correlation $(R=$ $-0.59, P<0.001)$ between genetic identity and geographic separation among the 12 populations. The equation for the regression line was $y=-21,165 x+$ 21,657 .

TABLE 5. Pairwise calculations of Nei's unbiased genetic identity (above diagonal) (31) and geographic separation (km) (below diagonal) based on 23 amplified fragment length polymorphism loci for 12 populations of Gibberella zeae (four New York atmospheric populations and eight populations from Zeller et al. [54]) across the United States ${ }^{\mathrm{a}}$

\begin{tabular}{|c|c|c|c|c|c|c|c|c|c|c|c|c|}
\hline & KS1 & $\mathrm{KS} 2$ & IL & MN & $\mathrm{OH}$ & VA & NY & MT & $\begin{array}{l}\text { Wheat- } \\
2004\end{array}$ & $\begin{array}{l}\text { Corn- } \\
2004\end{array}$ & $\begin{array}{l}\text { Corn- } \\
2003\end{array}$ & $\begin{array}{l}\text { Wheat- } \\
2002\end{array}$ \\
\hline KS1 & $\ldots$ & 0.994 & 0.995 & 0.984 & 0.992 & 0.985 & 0.967 & 0.938 & 0.970 & 0.959 & 0.958 & 0.952 \\
\hline KS2 & 74 & $\ldots$ & 0.992 & 0.988 & 0.992 & 0.984 & 0.968 & 0.948 & 0.982 & 0.974 & 0.976 & 0.969 \\
\hline $\mathrm{MN}$ & 891 & 868 & 1,202 & $\ldots$ & 0.986 & 0.988 & 0.967 & 0.960 & 0.982 & 0.977 & 0.976 & 0.970 \\
\hline $\mathrm{OH}$ & 1,194 & 1,121 & 619 & 1,369 & $\ldots$ & 0.990 & 0.967 & 0.954 & 0.979 & 0.969 & 0.970 & 0.968 \\
\hline VA & 1,428 & 1,360 & 778 & 1,737 & 386 & $\ldots$ & 0.961 & 0.940 & 0.984 & 0.967 & 0.977 & 0.966 \\
\hline NY & 1,649 & 1,574 & 1,140 & 1,573 & 532 & 692 & $\ldots$ & 0.925 & 0.957 & 0.953 & 0.954 & 0.949 \\
\hline Corn-2004 & 2,058 & 1,637 & 1,193 & 1,653 & 575 & 692 & 79 & 2,316 & 0 & 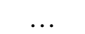 & 0.993 & 0.997 \\
\hline Corn-2003 & 2,058 & 1,637 & 1,193 & 1,653 & 575 & 692 & 79 & 2,316 & 0 & 0 & $\ldots$ & 0.997 \\
\hline Wheat-2002 & 2,058 & 1,637 & 1,193 & 1,653 & 575 & 692 & 79 & 2,316 & 0 & 0 & 0 & $\ldots$ \\
\hline
\end{tabular}

a Locations: $\mathrm{KS}=$ Kansas, $\mathrm{IL}=$ Illinois, $\mathrm{MN}=$ Minnesota, $\mathrm{OH}=$ Ohio, $\mathrm{VA}=$ Virginia, $\mathrm{NY}=\mathrm{New}$ York, and MT = Montana. 
mately 2,000 km) across the United States (53). Thus, based on sampling of populations from the atmosphere and infected cereals, there appears to be one large, interbreeding population of G. zeae in North America.

Recombination appears to have occurred in the NYAPs, as suggested by the high genotypic diversity observed in each of the populations. Low values of $G_{\mathrm{ST}}$ (fixation index) (ranging from 0.001 to 0.053 ; mean 0.014 ) and high values of $\mathrm{Nm}$ (effective migration rate per generation) (ranging from 9 to 411 ; mean 35) suggest that there has been significant genetic exchange among the NYAPs $(26,32)$. Relatively low levels of linkage disequilibrium were observed in the NYAPs. Two-locus linkage disequilibrium in the NYAPs was observed in a range of 1 to $4 \%$ of the locus pairs at $P<0.01$, and in a range of 6 to $10 \%$ of the locus pairs at $P<0.05$. None of the locus pairs showed evidence of linkage disequilibrium in all of the atmospheric populations. Three of the NYAPs (Wheat-2004, Corn-2004, and Wheat-2002) showed evidence of multilocus linkage disequilibrium. Though the NYAPs may be part of a large population of G. zeae that is potentially mating at random, relatively low levels of linkage disequilibrium imply that outcrossing is common and that the populations are not a result of a recent bottleneck or invasion. Other studies also have described relatively low levels of twolocus linkage disequilibrium $(52,53)$ and multilocus linkage disequilibrium (53) in populations of G. zeae. Although outcrossing under field conditions may contribute to high levels of diversity in populations of $G$. zeae, field isolates of $G$. zeae are homothallic and may reproduce sexually without a partner. Only a small amount of sexual recombination is needed to sustain high levels of genotypic diversity and the appearance of a randomly mating population (21).

Airborne ascospores, rather than asexual macroconidia, are thought to constitute the principal inoculum for the infection of wheat spikes (1) and corn ears (48). Several investigators have trapped spores of $G$. zeae from the atmosphere within and above crop canopies $(9,12,24,25,35,40,42-45)$. Viable spores of $G$. zeae have even been collected on the roof-top of buildings kilometers from potential inoculum sources (15). Studies with remote-controlled aircraft have demonstrated that viable spores of G. zeae are abundant in the lower atmosphere, at least $60 \mathrm{~m}$ above the earth's surface (24). The maintenance of high genotypic diversity in populations of $G$. zeae from around the world $(11,17,37,52,53)$ may result from long-distance transport punctuated by recombination events. Long-distance transport of $G$. zeae also suggests that the management of inoculum sources on a local scale would not be effective. Indeed, our data suggest that an effective "local" atmospheric population of $G$. zeae in New York might include most of the northern United States east of the Rocky Mountains.

Zeller et al. (53) suggested that genetic exchange among populations of $G$. zeae in the United States has occurred relatively frequently over time and over large geographic distances. The genetic identity between the NYAPs and the eight populations from Zeller et al. (53) were uniformly high (ranging from 0.92 to 0.99 ), suggesting that these populations were genetically similar and potentially part of the same large, interbreeding population of G. zeae in the United States. There was a significant negative correlation between genetic identity and geographic distance among these populations, suggesting that some regional differentiation could occur. Even if such differentiation occurs, these populations are still very similar and the level of differences relatively small (the lowest level of genetic identity between two populations was 0.937).

There also was evidence for intraregional differentiation in the populations as demonstrated by the comparisons of genetic identity among the four NYAPs, and between the four NYAPs and the New York population analyzed by Zeller et al. (53). This result may be related to the 4-year interval over which these populations were collected. Schmale et al. (41) found that temporal subpopu- lations of the NYAPs maintained high levels of genotypic diversity over different temporal scales (i.e., isolates collected on consecutive days, during day and night sampling periods, during 2-h sampling intervals throughout the night, and collected at different field locations in the same year). High genetic diversity in the atmosphere over time could result from continuous mixing of atmospheric inoculum sources of G. zeae, potentially from multiple origins over large geographic distances (41). Thus, small differences in population structure among regional populations of G. zeae may reflect the time that is required for alleles to move or establish themselves within populations separated by large geographic distances.

Strains of G. zeae introduced into the United States could interbreed with native strains. If so, individual traits could be incorporated relatively quickly into the existing populations and efficiently dispersed throughout the country. Under this scenario, it appears unlikely that introduced strains of $G$. zeae would maintain a unique clonal identity. Individual (or very closely linked) gene combinations are more likely to be incorporated into the genome than are multilocus traits that are dispersed across the genome. Immigrant strains of G. zeae with higher aggressiveness or altered toxin profiles, if transported long distances through the atmosphere, could spread rapidly across North America and displace native strains.

New strategies for managing FHB and GER may result from a better understanding of the population genetic structure of G. zeae. Our observation of high genetic diversity in atmospheric populations of $G$. zeae is consistent with long-distance transport and at least episodic recombination in populations of the pathogen. Risk assessment models for predicting FHB epidemics have been developed $(10,18)$; however, these models do not consider that inoculum deposited in local fields may have been transported through the atmosphere from multiple origins over large geographic distances. If a large, regional source of atmospheric inoculum of G. zeae exists, localized management practices (e.g., crop rotation or tillage) may not sufficiently reduce the risk of FHB or GER in individual fields.

\section{ACKNOWLEDGMENTS}

This research was supported in part by grants to G. C. Bergstrom and J. F. Leslie from the U.S. Wheat and Barley Scab Initiative (USWBSI) of the U.S. Department of Agriculture (USDA) under Agreement Numbers 58-5430-2-327, 59-0790-9-027, and 59-0790-4-093. Any opinions, findings, conclusions, or recommendations expressed in this publication are those of the authors and do not necessarily reflect the view of the USDA. This research also was supported by Cornell University Hatch Project NYC153433 and the Kansas Agricultural Experiment Station. This is manuscript no. 06-162-J from the Kansas Agricultural Experiment Station, Manhattan. We thank J. E. Jurgenson for his help in finding locations for some of our AFLP markers on the genetic map of G. zeae.

\section{LITERATURE CITED}

1. Andersen, A. L. 1948. The development of Gibberella zeae headblight of wheat. Phytopathology 38:595-611.

2. Bennett, R. S., Milgroom, M. G., and Bergstrom, G. C. 2005. Population structure of seedborne Phaeosphaeria nodorum on New York wheat. Phytopathology 95:300-305.

3. Bissegger, M., Rigling, D., and Heiniger, U. 1997. Population structure and disease development of Cryphonectria parasitica in European chestnut forests in the presence of natural hypovirulence. Phytopathology 87:50-59.

4. Bowden, R. L., and Leslie, J. F. 1992. Nitrate-nonutilizing mutants of Gibberella zeae (Fusarium graminearum) and their use in determining vegetative compatibility. Exp. Mycol. 16:308-315.

5. Bowden, R. L., and Leslie, J. F. 1999. Sexual recombination in Gibberella zeae. Phytopathology 89:182-188.

6. Bowden, R. L., Leslie, J. F., Lee, J., and Lee, Y. W. 2004. Cross fertility of Gibberella zeae. Page 554 in: Proc. Second Int. Symp. Fusarium Head Blight, Orlando, FL. 
7. Burgess, L. W., Summerell, B. A., Bullock, S., Gott, K. P., and Backhouse, D. 1994. Laboratory Manual for Fusarium Research, 3rd ed. University of Sydney, Australia.

8. Del Ponte, E. M., Shah, D. A., and Bergstrom, G. C. 2003. Spatial patterns of Fusarium head blight in New York wheat fields suggest role of airborne inoculum. Online. Plant Health Progress doi:10.1094/PHP-20030418-01-RS.

9. De Luna, L., Bujold, I., Carisse, O., and Paulitz, T. C. 2002. Ascospore gradients of Gibberella zeae from overwintered inoculum in wheat fields. Can. J. Plant Pathol. 24:457-464.

10. De Wolf, E. D., Madden, L. V., and Lipps, P. E. 2003. Risk assessment models for wheat Fusarium head blight epidemics based on within-season weather data. Phytopathology 93:428-435.

11. Dusabenyagasani, M., Dostaler, D., and Hamelin R. C. 1999. Genetic diversity among Fusarium graminearum strains from Ontario and Quebec. Can. J. Plant Pathol. 21:308-314.

12. Fernando, W. G. D., Miller, J. D., Seaman, W. L., Seifert, K., and Paulitz, T. A. 2000. Daily and seasonal dynamics of airborne spores of Fusarium graminearum and other Fusarium species sampled over wheat plots. Can. J. Bot. 78:497-505.

13. Fisher, N. L., Burgess, L. W., Toussoun, T. A., and Nelson, P. E. 1982. Carnation leaves as a substrate and for preserving cultures of Fusarium species. Phytopathology 72:151-153.

14. Flett, B. C., McLaren, N. W., and Wehner, F. C. 1998. Incidence of ear rot pathogens under alternating corn tillage practices. Plant Dis. 82:781-784.

15. Francl, L., Shaner, G., Bergstrom, G., Gilbert, J., Pedersen, W., DillMackey, R., Sweets, L., Corwin, B., Jin, Y., Gallenberg, D., and Wiersma, J. 1999. Daily inoculum levels of Gibberella zeae on wheat spikes. Plant Dis. 83:662-666.

16. Fry, W. E., Goodwin, S. B., Matuszak, J. M., Spielman, L. J., Milgroom, M. G., and Drenth, A. 1992. Population genetics and intercontinental migrations of Phytophthora infestans Annu. Rev. Phytopathol. 30:107130.

17. Gale, L. R., Chen, L.-F., Hernick, C. A., Takamura, K., and Kistler, H. C. 2002. Population analysis of Fusarium graminearum from wheat fields in eastern China. Phytopathology 92:1315-1322.

18. Hooker, D. C., Schaafsma, A. W., and Tamburic-Ilincic, L. 2002. Using weather variables pre- and post-heading to predict deoxynivalenol content in winter wheat. Plant Dis. 86:611-619.

19. Klittich, C. J. R., and Leslie, J. F. 1988. Nitrate reduction mutants of Fusarium moniliforme (Gibberella fujikuroi). Genetics 118:417-423.

20. Jurgenson, J. E., Bowden, R. L., Zeller, K. A., Leslie, J. F., Alexander, N. A., and Plattner, R. D. 2002. A genetic map of Gibberella zeae (Fusarium graminearum). Genetics 160:1452-1460.

21. Leslie, J. F., and Klein, K. K. 1996. Female fertility and mating-type effects on effective population size and evolution in filamentous fungi. Genetics 144:557-567.

22. Lewontin, R. C. 1964. The interaction of selection and linkage. I. General considerations; heterotic models. Genetics 49:49-67.

23. Ma, Z., Luo, Y., and Michailides, T. J. 2004. Spatiotemporal changes in the population structure of Botryosphaeria dothidea from California pistachio orchards. Phytopathology 94:326-332.

24. Maldonado-Ramirez, S. L., Schmale, D. G., Shields, E. J., and Bergstrom, G. C. 2005. The relative abundance of viable spores of Gibberella zeae in the planetary boundary layer suggests the role of long-distance transport in regional epidemics of Fusarium head blight. Agric. For. Meteorol. 132:20-27.

25. Markell, S. G., and Francl, L. J. 2003. Fusarium head blight inoculum: Species prevalence and Gibberella zeae spore type. Plant Dis. 87:814820.

26. McDermott, J. M., and McDonald, B. A. 1993. Gene flow in plant pathosystems. Annu. Rev. Phytopathol. 31:353-373.

27. McMullen, M. P., Jones, R., and Gallenberg, D. 1997. Scab of wheat and barley: A re-emerging disease of devastating impact. Plant Dis. 81:13401348 .

28. Milgroom, M. G. 1996. Recombination and the multilocus structure of fungal populations. Annu. Rev. Phytopathol. 43:457-477.

29. Milgroom, M. G., and Fry, W. E. 1997. Contributions of population genetics to plant disease epidemiology and management. Adv. Bot. Res. 24:1-30.

30. Nei, M.1973. Analysis of gene diversity in subdivided populations. Proc. Natl. Acad. Sci. USA 70:3321-3323.
31. Nei, M. 1978. Estimation of average heterozygosity and genetic distance from a small number of individuals. Genetics 89:583-590.

32. Nei, M. 1987. Molecular Evolutionary Genetics. Columbia University Press, New York.

33. O’Donnell, K., Kistler, H. C., Tacke, B. K., and Casper, H. H. 2000. Gene genealogies reveal global phylogenetic structure and reproductive isolation among lineages of Fusarium graminearum, the fungus causing wheat scab. Proc. Natl. Acad. Sci. USA 97:7905-7910.

34. O'Donnell, K., Ward, T. J., Geiser, D. M., Kistler, H. C., and Aoki, T. 2004. Genealogical concordance between the mating type locus and seven other nuclear genes supports formal recognition of nine phylogenetically distinct species within the Fusarium graminearum clade. Fungal Genet. Biol. 41:600-623.

35. Paulitz, T. C. 1996. Diurnal release of ascospores by Gibberella zeae in inoculated wheat plots. Plant Dis. 80:674-678.

36. Salas, B., Steffenson, B. J., Casper, H. H., Tacke, B., Prom, L. K., Fetch, T. G., and Schwarz, P. B. 1999. Fusarium species pathogenic to barley and their associated mycotoxins. Plant Dis. 83:667-674.

37. Schilling, A. G., Miedaner, T., and Geiger, H. H. 1997. Molecular variation and genetic structure in field populations of Fusarium species causing head blight in wheat. Cereal Res. Commun. 25:549-554.

38. Schmale, D. G., Arntsen, Q. A., and Bergstrom, G. C. 2005. The forcible discharge distance of ascospores of Gibberella zeae. Can. J. Plant Pathol. 27:376-382.

39. Schmale, D. G., and Bergstrom, G. C. 2003. Fusarium head blight. The Plant Health Instructor. DOI:10.1094/PHI-I-2003-0612-01

40. Schmale, D. G., and Bergstrom, G. C. 2004. Spore deposition of the ear rot pathogen, Gibberella zeae, inside corn canopies. Can. J. Plant Pathol. 26:591-595.

41. Schmale, D. G., Leslie, J. F., Saleh, A. A., Shields, E. J., and Bergstrom, G. C. Temporal scales of genetic diversity within New York atmospheric populations of Gibberella zeae. Page 150 in: 2005 Natl. Fusarium Head Blight Forum, Milwaukee, WI.

42. Schmale, D. G., Shah, D. A., and Bergstrom, G. C. 2005. Spatial patterns of viable spore deposition of Gibberella zeae in wheat fields. Phytopathology 95: 472-479.

43. Schmale, D. G., Shah, D. A., and Bergstrom, G. C. 2005. Spatial patterns of viable spore deposition of the corn ear rot pathogen, Gibberella zeae, in first-year corn fields. Can. J. Plant Pathol. 27:225-233.

44. Schmale, D. G., Shields, E. J., and Bergstrom, G. C. 2002. Airborne populations of Gibberella zeae: Spatial and temporal dynamics of spore deposition in a localized Fusarium head blight epidemic. Page 178 in: Proc. 2002 Natl. Fusarium Head Blight Forum, Erlanger, KY.

45. Schmale, D. G., Shields, E. J., and Bergstrom, G. C. 2006. Night-time spore deposition of the Fusarium head blight pathogen, Gibberella zeae. Can. J. Plant Pathol. 28:100-108.

46. Shaner, G. E. 2003. Epidemiology of Fusarium head blight of small grain cereals in North America. Pages 84-119 in: Fusarium Head Blight of Wheat and Barley. K. J. Leonard. and W. Bushnell, eds. The American Phytopathological Society, St. Paul, MN.

47. Smouse, P. E., and Neel, J. V. 1977. Multivariate analysis of gametic disequilibrium in the Yanomama. Genetics 85:733-752.

48. Sutton, J. C. 1982. Epidemiology of wheat head blight and maize ear rot caused by Fusarium graminearum. Can. J. Plant Pathol. 4:195-209.

49. Vos, P., Hogers, R., Bleeker, M., Reijans, M., van de Lee, T., Hornes, M., Frijters, A., Pot, J., Peleman, J., Kuiper, M., and Zabeau, M. 1995. AFLP: A new technique for DNA fingerprinting. Nucleic Acids Res. 23:44074414.

50. Walker, S. L., Leath, S., Hagler, W. M., Jr., and Murphy, J. P. 2001. Variation among isolates of Fusarium graminearum associated with Fusarium head blight in North Carolina. Plant Dis. 85:404-410.

51. Weir, B. S. 1979. Inferences about linkage disequilibrium. Biometrics 53:235-254.

52. Zeller, K. A., Bowden, R. L., and Leslie, J. F. 2003. Diversity of epidemic populations of Gibberella zeae from small quadrats in Kansas and North Dakota. Phytopathology 93:874-880.

53. Zeller, K. A., Bowden, R. L., and Leslie, J. F. 2004. Population differentiation and recombination in wheat scab populations of Gibberella zeae from the United States. Mol. Ecol. 13:563-557.

54. Zeller, K. A., Jurgenson, J. E., El-Assiuty E. M., and Leslie, J. F. 2000. Isozyme and amplified fragment length polymorphisms (AFLPs) from Cephalosporium maydis in Egypt. Phytoparasitica 28:121-130. 